\title{
O PROGRAMA ESCOLA DE CONSELHOS DA UNIVERSIDADE FEDERAL DE MATO GROSSO DO SUL
}

\author{
Antonio José Angelo Motti1 \\ ORCID: 0000-0003-4535-3144 \\ Carina Elisabeth Maciel \\ ORCID: 0000-0003-3765-3139
}

Francieli Piva Borsato

ORCID: 0000-0001-7758-6319

Resumo: O Programa Escola de Conselhos é um programa de extensão vinculado à Universidade Federal de Mato Grosso do Sul (UFMS), em funcionamento desde 1997, que aporta diferentes ações e projetos no campo dos Direitos Humanos e Sociais, em especial aquelas destinadas ao aprimoramento de políticas públicas voltadas às áreas da criança e do adolescente, do trabalho, emprego e renda, do controle social e das minorias étnicas e raciais. Este artigo tem como objetivo apresentar parte da análise dos resultados produzidos pelo Programa Escola de Conselhos enquanto ação de Extensão Universitária. A investigação foi desenvolvida utilizando a pesquisa bibliográfica e documental e se configura como um estudo de caso, uma vez que consiste em um Programa específico e singular, materializado em uma Universidade Pública Federal e em um determinado contexto histórico. Os dados foram coletados em documentos, relatórios e editais institucionais e do Programa Escola de Conselhos.

Palavras-chave: Escola de Conselhos. Políticas Públicas. Extensão Universitária.

1 Possui graduação em FORMAÇÃO DE PSICOLOGO, Pós-Graduado em nível de Especialização em Psicologia Social. Vinculado a Universidade Federal de Mato Grosso do Sul desde 1996 onde ocupa cargo de Técnico em Assuntos Educacionais. E-mail: antonio.motti@ufms.br.

2 Possui graduação em Pedagogia pela UFMS; Mestrado em Educação pela UCDB; Doutorado em Educação pela UFMS e Pós-Doutorado em Educação pela UNEMAT. Docente no PPGEDU/FAED/ UFMS. Coordenadora do GEPPES/MB e do GEPIEE.E-mail: carina.maciel@ufms.br.

3 Assistente Social graduada pela Universidade Estadual do Oeste do Paraná, Mestre em Política Social e Serviço Social pela UNIOESTE e atua como Assistente Social na UFMS. E-mail: pivinha_21@ hotmail.com. 


\begin{abstract}
The School of Counseling Program is an extension program linked to the Federal University of Mato Grosso do Sul (UFMS), which has been in operation since 1997, providing different actions and projects in the field of Human and Social Rights, especially those aimed at improving policies children and adolescents, work, employment and income, social control and ethnic and racial minorities. This article aims to present part of the analysis of the results produced by the Council School Program as a University Extension action. The research was developed through bibliographical and documentary research and is configured as a case study, since it consists of a specific and unique Program, materialized in a Federal Public University and in a certain historical context. The data were collected in documents, reports and institutional announcements and the School of Councils Program.
\end{abstract}

Key-words: Council School. Public Policy. University Extension.

Resumen: El Programa Escuela de Consejos es un programa de extensión vinculado a la Universidad Federal de Mato Grosso do Sul (UFMS), en funcionamiento desde 1997, que aporta diferentes acciones y proyectos en el campo de los Derechos Humanos y Sociales, en especial aquellas destinadas al perfeccionamiento de políticas públicas dirigidas a las áreas del niño y del adolescente, del trabajo, empleo y renta, del control social y de las minorías étnicas y raciales. Este artículo tiene como objetivo presentar parte del análisis de los resultados producidos por el Programa Escuela de Consejos como acción de Extensión Universitaria, por medio de relato histórico. La investigación fue desarrollada por medio de investigación bibliográfica y documental y se configura como un estudio de caso, ya que consiste en un Programa específico y singular, materializado en una Universidad Pública Federal y en un determinado contexto histórico. Los datos fueron recolectados en documentos, informes y ediciones institucionales y del Programa Escuela de Consejos.

Palabras claves: Escuela de Consejos. Políticas públicas. Extensión Universitaria.

Submetido em: 20/12/2018

Aceito em: 22/12/2018

\title{
INTRODUÇÃO
}

A extensão universitária, sob o princípio constitucional da indissociabilidade entre ensino, pesquisa e extensão, pressupõe uma postura da Universidade na sociedade em que se insere (FORPROEX, 2012). A universidade tem como uma tarefa, em sua relação simbiótica com a sociedade, tentar responder às suas demandas e expectativas, reconhecendo a diversidade que é parte dela. E a extensão universitária tem um papel central neste processo ao configurar-se como um potencial articulador entre o conhecimento adquirido e produzido na Universidade à construção de possíveis respostas as questões que se colocam como problemas fundamentais em cada tempo histórico. 
Enquanto modalidade de extensão universitária, o Programa Escola de Conselhos - PEC surgiu em 1997 como uma proposta de formação de conselheiros no campo dos direitos da criança e adolescente, respondendo a uma demanda da sociedade na qual era imperativo a necessidade de implantação do Sistema de Garantia de Direitos, preconizado pelo Estatuto da Criança e Adolescente, aprovado em 1993. Desde então, o PEC foi mobilizando um conjunto de iniciativas, englobando diferentes ações e projetos de extensão no campo dos Direitos Humanos e Sociais, em especial as ações destinadas ao aprimoramento de políticas públicas voltadas às áreas da criança e do adolescente; do trabalho, emprego e renda; do controle social e das minorias étnicas e raciais (MOTTI, et al, 2017).

Para desenvolver o presente trabalho recorremos à história do programa, traçando as ações de extensão organizadas e desenvolvidas por ele, destacando os objetivos e motivações de cada projeto, as publicações e os principais resultados destes. A metodologia desenvolvida foi pesquisa bibliográfica e documental, apresentando os dados coletados em sequência cronológica.

\section{O PROGRAMA ESCOLA DE CONSELHOS: ORIGEM E DESENVOLVIMENTO}

O Programa Escola de Conselhos é resultado de uma história iniciada em 1997 com o projeto de extensão Centro de Estudos, Formação e Informação em Políticas Públicas Voltadas ao Atendimento e Defesa dos Direitos da Criança e do Adolescente (CEFIPP). No âmbito deste projeto, encontravam-se três ações: Escola de Conselhos, Banco de Dados e Centro de Documentação. O projeto foi aprovado pelo Colegiado do Departamento de Ciências Humanas (DCH) do Centro de Ciências Humanas e Sociais (CCHS).

Depois de aprovado no âmbito do DCH/CCHS, o Projeto de Extensão foi apresentado ao Departamento da Criança, da Secretaria Especial de Direitos Humanos do Ministério da Justiça (SEDH), visando ao financiamento do $1^{\circ}$ Curso de Formação em Políticas Públicas para Infância e Juventude, na condição de atividade da Escola de Conselhos, que prevista ações de capacitação de conselheiros estaduais e municipais dos direitos da criança e do adolescente.

Em março de 1998, a UFMS firmou convênio com a Secretaria Especial de Direitos Humanos do Ministério da Justiça, onde se vinculava ao 
Departamento da Criança, visando o recebimento de recursos para execução das atividades do Projeto $1^{\circ}$ Curso de Formação.

Em junho de 1999, o "1 Curso de Formação" foi concluído com a certificação de 45 alunos. Na ocasião, foi lançada a primeira publicação da Escola de Conselhos intitulada "Cadernos Caminhos para a Cidadania - Infância e Juventude, Desafios para o Século XXI", com artigos dos professores e alunos concluintes do Curso.

A partir de então, diversos convites foram apresentados por algumas prefeituras do interior do estado de Mato Grosso do Sul, de outros estados vizinhos, como São Paulo e Mato Grosso e, de outros mais distantes, como foram os casos do Rio de Janeiro, Santa Catarina, Piauí, Roraima, Pará, Amapá e Amazonas, para que equipe do projeto promovesse formação de conselheiros e contribuísse com a organização da rede de proteção à infância destes locais.

Outra ação proposta pelo Programa em 1999 e efetivada em meados dos anos 2000 foi a oferta de um Curso de Formação e Informação de Políticas Públicas de Direitos Humanos. Essa proposta surgiu a partir da provocação realizada pelos Conselhos Estaduais dos Direitos Humanos, Direitos do Negro, Direitos da Mulher, da Pessoa com Deficiência e de Combate a Drogas, para que o programa oferecesse um curso com o objetivo de capacitar os conselheiros estaduais e também os agentes públicos municipais que atuavam na execução de políticas, programas, serviços e ações de atendimento a esses segmentos da sociedade. O curso foi planejado nos moldes do primeiro Curso de Formação e Informação em Políticas Públicas para Infância e Adolescência, organizado em módulos de 40 horas aulas, com uma carga horária final de 220 horas/aula. Concluíram o curso 45 alunos oriundos de 22 municípios do estado de MS e dos Conselhos Estaduais proponentes da ação.

Essas ações de extensão universitária ofereciam uma ampla visibilidade externa da Escola de Conselhos e por decorrência, da própria UFMS e dos Departamentos e Cursos envolvidos. A realização dessas ações desencadeava diversos projetos de extensão universitária, e conforme cada norma regulamentadora, eram previstas a participação de estudantes dos cursos de graduação, em sua grande maioria dos cursos de Pedagogia, Psicologia, História, Jornalismo, Administração, Direito, Letras, Ciência da Computação. Alguns projetos permitiam, com financiamento externo, o pagamento de bolsa para extensionistas e mesmo para colaboradores externos. Outros projetos não foram executados com pagamento de bolsas, porém foi assegurada 
a participação de extensionistas da graduação e dos programas de pós-graduação. Muitos alunos que participaram das atividades de extensão, como bolsistas ou não, escolheram temas relacionados às áreas de atuação dos projetos para seus Trabalhos de Conclusão de Curso ou mesmo como objeto de pesquisa na pós-graduação.

No final de 1999, a equipe apresentou novo projeto ao Departamento da Criança visando o financiamento do "2º Curso de Formação em Políticas Públicas para Infância e Juventude", cujos recursos foram liberados no início de 2000, quando se iniciaram as atividades nos mesmos moldes do "1 Curso", visando à capacitação de novos conselheiros municipais e tutelares. Assim como na primeira versão, a equipe recebeu pedido de matrícula de conselheiros de outros estados. Em 2001 a Editora UFMS publicou um livro com os resultados desse processo.

Dada a complexidade das demandas surgidas por parte dos municípios, a administração da UFMS entendeu que o Projeto deveria migrar do Departamento de Ciências Humanas e Sociais para a Pró-reitoria de Extensão. Dessa forma, em 1999, o projeto e a equipe de técnicos passaram a ser vinculados ao gabinete do Pró-reitor de Extensão, Cultura e Esporte da UFMS.

O nome do projeto de extensão "Centro de Estudos, Formação e Informação em Políticas Públicas Voltadas ao Atendimento e Defesa dos Direitos da Criança e do Adolescente (CEFIPP)" foi involuntariamente caindo em desuso, pois a atividade Escola de Conselhos, inicialmente pensada como a agregadora das ações de capacitação, acabou por se constituir em uma expressão pela qual as pessoas das instituições e os alunos identificavam o conjunto de ações desenvolvidas pelo Projeto do CEFIPP.

Em 2001, o Colegiado Nacional de Conselheiros Tutelares propôs ao Departamento Nacional dos Direitos da Criança, da Secretaria Especial dos Direitos Humanos do Ministério da Justiça, que financiasse uma capacitação nacional dos Conselhos Tutelares, seguindo a metodologia iniciada no Projeto Escola de Conselhos. O Departamento buscou a equipe do projeto Escola de Conselhos para que apresentasse uma proposta e atendesse aquela demanda. A proposta "Formação Nacional de Conselheiros Tutelares" foi aprovada e suas atividades iniciaram ainda em 2001, quando foram capacitados dois conselheiros tutelares por Unidade da Federação, em módulos de 40 horas.

As ações foram realizadas em Campo Grande (MS) e tinham como finalidade adicional promover o modelo desenvolvido pela UFMS, para que outros 
estados se estruturassem e pudessem oferecer formação para seus Conselheiros. Com o desenvolvimento desse projeto, iniciou-se o processo de nacionalização da ideia e, em consequência, a ampliação da procura permanente de outros estados por informações com vistas à organização de iniciativa semelhante em sua localidade e, em busca da possibilidade de ofertar, de forma sistemática e permanente, formação de agentes públicos e conselheiros no campo dos direitos humanos de crianças e adolescentes.

Ainda em decorrência das demandas externas, o Conselho Nacional dos Direitos da Criança e do Adolescente (CONANDA), conhecedor da linha editorial "Cadernos Caminhos para a Cidadania", propôs à equipe da Escola de Conselhos que publicasse o relatório avaliativo sobre o nível de cumprimento dos compromissos assumidos pelo Brasil enquanto signatário da Convenção Internacional dos Direitos da Criança e do Adolescente, no marco dos 10 anos de vigência daquela legislação internacional. Esse relatório foi produzido pela equipe de pesquisadores do Centro de Referência, Estudos e Ações Sobre Crianças e Adolescentes (CECRIA). Fruto dessa provocação e, com interveniência da Fundação de Apoio à Pesquisa, ao Ensino e à Cultura (FAPEC), o relatório foi produzido, editado e publicado, em 2001, pela Editora UFMS.

Em 2002, o Departamento Nacional dos Direitos da Criança da Secretaria Especial dos Direitos Humanos, do Ministério da Justiça, buscou a equipe do Projeto para que apresentasse uma proposta de formação dos Conselheiros Tutelares das cidades de Pacaraima (RR), Manaus (AM), Rio Branco (AC), Campina Grande (PB), Feira de Santana (BA) e Corumbá (MS). Esta ação comporia um grande projeto piloto de integração de políticas públicas de enfrentamento à exploração sexual de crianças e adolescentes e tráfico humano. O projeto foi aprovado e sua execução iniciada em março de 2003. A proposta foi apresentada sob o título "Escola de Conselhos: A Comunicação como Estratégia para o Fortalecimento das Ações do Sistema de Garantia dos Direitos no Enfrentamento à Violência Sexual contra Crianças e Adolescentes - Ações de Continuidade".

No início do processo de execução deste projeto, decorrente de pactos entre o Ministério da Justiça com o Ministério do Desenvolvimento Social e a Agência Americana para Desenvolvimento Internacional, as funções da equipe no projeto e, por consequência as atividades, foram totalmente reordenadas, expandindo o caráter de parceiro responsável pela capacitação, para parceiro responsável pelo desenvolvimento e sistematização da metodologia 
do "Programa de Ações Integradas e Referenciais de Enfrentamento à Violência Sexual contra Crianças e Adolescentes no Território Brasileiro - PAIR”, instituído pelo DCA, a partir desse ano.

Os acordos firmados com o Departamento Nacional dos Direitos da Criança da Secretaria Especial dos Direitos Humanos do Ministério da Justiça e a própria Agência Americana, consolidaram o caráter nacional dessa inciativa de extensão universitária, na medida em que o escopo do seu trabalho passou a alcançar formalmente o território brasileiro. Essa ação perdurou até 2006, quando culminou em duas publicações pela Editora da UFMS, conforme QUADRO1.

Decorrente do processo de disseminação da metodologia do PAIR no território brasileiro, o Ministério da Educação, por meio da Secretaria de Educação Continuada, Alfabetização, Diversidade e Inclusão (SECADI), fomentou com recursos financeiros e apoio técnico a implantação do Projeto "Escola que Protege". A equipe do Programa Escola de Conselhos foi convidada a desenvolver o Projeto em três municípios de Mato Grosso do Sul: Campo Grande, Paranaíba e Ponta Porã. Essa ação previa a formação de profissionais da rede de educação pública, utilizando-se de material produzido pela Secretaria de Educação Continuada, Alfabetização, Diversidade e Inclusão (Secadi), bem como produção e publicação de conteúdos complementares. Essa ação promoveu formações durante o ano de 2006, sendo reeditada nos dois anos seguintes. Essa ação ainda acabou por gerar um novo projeto voltado à Educação para Sexualidade, Equidade, Gênero e Diversidade Sexual, oferecido ao mesmo público.

Como produto dessa ação, em 2009, a Editora UFMS publicou um Kit de Conteúdos para Capacitação de profissionais em educação composto por três cartilhas, um caderno e um vídeo produzido nos estúdios da Anima Mundi, conforme QUADRO 1.

Ainda em 2005, a Secretaria de Direitos Humanos da Presidência da República resolveu pela expansão nacional da experiência do PAIR, reforçando a área de cobertura dos seis estados abrangidos e buscando a implantação em mais cinco Unidades da Federação. Novamente, a equipe do Programa foi convidada a coordenar o processo de implantação do Programa, estabelecendo parcerias com as Universidades Federais do Amazonas, Acre, Maranhão, Minas Gerais, Pernambuco, Rio Grande do Norte e Roraima, bem como com as Universidades Estaduais da Bahia, Ceará e Paraíba. 
A participação da equipe do Programa Escola de Conselhos nesses onze Estados deu origem ao Projeto de Extensão denominado "Disseminação da Metodologia do PAIR" que implicou no repasse da metodologia, transferência das tecnologias desenvolvidas no processo e permanente assistência e apoio técnico para o seu desenvolvimento e na organização de um web portal do Programa com diversas finalidades, destacando: a apresentação pública e permanente do PAIR, conceitos, objetivo, metas, metodologia, abrangência, produtos, notícias, campanhas, relatórios, monitoramento (pair.ledes.net).

Ainda em 2006, o Governo do Estado de Mato Grosso do Sul, por meio da Secretaria de Estado de Assistência Social e Trabalho buscou a equipe do Programa Escola de Conselhos para implantar uma ação de Formação Continuada de Socioeducadores visando à capacitação dos técnicos e educadores que atuavam em Unidades Educacionais de Internação (Uneis), em cinco cidades do estado de MS.

Um Programa de Formação foi elaborado, em conjunto com técnicos daquela Secretaria e foi efetivado a partir de 2007 por meio da realização de 10 módulos de capacitação, dois deles estaduais - reunindo os trabalhadores das oito Unidades- e um módulo local, em cada uma das Unidades, perfazendo um total de 120 horas/aulas.

Nos nove anos seguintes, novas edições dessa atividade foram realizadas, buscando a atualização e evolução dos temas de interesse, em especial, de assuntos decorrentes da Implantação do Sistema Nacional de Socioeducação SINASE, inicialmente fruto de uma deliberação do Conanda (Resolução do Conanda 119/2006), transformada em legislação federal em 2012 (Lei Federal no 12.594/2012). Com esta legislação, preceitos legais, novas resoluções e outros atos foram editados pelos órgãos e colegiados setoriais, visando normatizar a atuação das políticas de Assistência Social, Educação e Saúde, demandando novas formações. As atividades de formação foram desenvolvidas até 2015, e publicados, neste período, sete livros.

Em 2008, durante a abertura da 14 ${ }^{\text {a }}$ Reunião de Altas Autoridades em Direitos Humanos e Chancelarias do Mercosul e Estados Associados (RAADH), os governos da Argentina, Brasil, Paraguai e Uruguai firmaram um acordo visando à implantação de rede regional de enfrentamento do tráfico de crianças e adolescentes para fins de exploração sexual em regiões de fronteira, denominado Estratégia Regional de Enfrentamento ao Tráfico de Crianças e Adolescentes para fins de Exploração Sexual no Mercosul - PAIR MERCOSUL. 
Os organismos executores designados pelos Governos dos países envolvidos foram: pelo Uruguai, Instituto do Niño y Adolescente do Uruguay (INAU) e o Ministerio de Educación y Cultura; pela Argentina, a Secretaría de Derechos Humanos do Ministerio de Justicia e Derechos Humanos; pelo Paraguai, o Ministerio de Educación y Cultura e a Secretaría Nacional de la Niñez y Adolescencia; e pelo Brasil, a Secretaria dos Direitos Humanos da Presidência da República por meio da Secretaria Nacional de Promoção dos Direitos Humanos de Crianças e Adolescentes.

Esse acordo teve apoio do Banco Interamericano de Desenvolvimento (BID) que garantiu a maior parte dos custos orçados para o desenvolvimento dessa ação. Coube à equipe do Programa Escola de Conselhos da Universidade Federal de Mato Grosso do Sul a tarefa de gerenciar e coordenar tecnicamente as atividades desenvolvidas em cada país, tendo como elemento metodológico o PAIR.

O programa abrangeu quinze municípios de fronteira entre Brasil, Argentina, Paraguai e Uruguai. Por se tratar da aplicação de uma metodologia já testada e validada no território nacional por meio do PAIR, os objetivos, os métodos e as atividades guardaram muitas semelhanças.

O objetivo principal dessa ação no Mercosul foi a de implantar uma estratégia regional de enfrentamento da violência sexual contra crianças e adolescentes e tráfico para esses fins nas quinze cidades gêmeas das fronteiras entre Brasil, Argentina, Uruguai e Paraguai, construída a partir de experiências validadas e sistematizadas de mobilização, organização, fortalecimento e integração de redes e serviços locais de prevenção, atendimento, defesa e responsabilização.

Esse trabalho foi desenvolvido em cooperação com instituições públicas e sociais apresentadas pelas instituições governamentais como suas representantes na execução técnica das atividades, cabendo aos governos realizar as articulações políticas visando ao envolvimento e compromisso dos governos municipais, estaduais/ departamentais/ provinciais das regiões abrangidas no programa. O grupo com as instituições/organizações locais que executaram as ações foi assim composto: pela Argentina, o Comité Argentino de Seguimiento y Aplicación de la Convención Internacional sobre los Derechos del Niño - CASACIDN; pelo Brasil, além do Programa Escola de Conselhos da UFMS, que exerceu o papel de coordenação técnica geral, a Universidade Federal de Rio Grande (FURGS) e a Universidade Estadual do Oeste do Paraná 
(UNIOESTE); pelo Paraguai, o Centro de Estudios en Derechos Humanos, Niñez y Juventud (CENIJU); e pelo Uruguai, a Universidade Nacional por meio das Faculdades de Psicologia, Direito e Ciências Sociais.

A exemplo do PAIR, depois de definidos os conteúdos dos instrumentais, foi colocado no portal também desenvolvido pela Laboratório de Engenharia de Software da UFMS. Da mesma forma, no portal foi criado um ambiente interno para que os pesquisadores de cada estado pudessem lançar todas as informações colhidas em cada uma das entrevistas e gerar relatórios qualitativos e quantitativos, disponibilizados no espaço público do portal (mercosul. ledes.net).

Como resultado do Seminário, foi aprovada pelas autoridades da Iniciativa Niñosur, a proposta de Resolução que criou o Plano Regional de Enfrentamento ao Tráfico de Crianças e Adolescentes em regiões de Fronteira, consolidado por uma Resolução no âmbito da Reunião de Altas Autoridades em Direitos Humanos do Mercosul (RAADH). Durante o Seminário, foi lançada a publicação do Plano.

Em 2008, o Programa Escola de Conselhos, em colaboração com a Secretaria de Estado de Assistência Social e Trabalho, apresentou à Secretaria de Direitos Humanos e conseguiu aprovação para dar continuidade ao processo de Capacitação de Conselheiros Municipais e Tutelares dos municípios de Mato Grosso do Sul. As atividades foram realizadas no período de julho de 2008 a dezembro de 2009. A capacitação teve a participação de conselheiros de 73 dos 79 municípios do estado, envolvendo cerca de 20 professores, em sua maioria do quadro de docentes e técnicos da UFMS. Um dos produtos desse curso foi a publicação pela Editora UFMS.

Em 2009, a Prefeitura Municipal de Campo Grande, decorrente de uma cooperação firmada com a Agenzia Regional per la Adozioni Internazionali - ARAI, buscou o apoio da equipe do Programa Escola de Conselhos para desenvolver e executar uma proposta de fortalecimento das ações de acolhimento institucional, prevendo quatro ações básicas: diagnóstico da situação das unidades de acolhimento; construção e execução de matriz de capacitação para os trabalhadores da área; produção de material didático referencial para capacitação e intercâmbio com a Rede de Proteção da Região do Piemonte, na Itália. Os trabalhos foram desenvolvidos a partir do final de 2009, estendendo-se até meados de 2011, período em que ocorreram as ações de intercâmbio com visita às Comunas Referenciadas, na região do Piemonte, e à capital 
Turim, bem como recepção em Campo Grande de um grupo de agentes públicos italianos que desenvolviam serviço de referência na proteção de crianças. Além de promover a formação de pessoas que atuam em toda a rede de acolhimento, na cidade de Campo Grande, essa ação teve como produto a edição e publicação, em 2011, de um Construção da Rede de Proteção à Criança ao Adolescente e suas Famílias - Caderno de Textos.

Em 2009, o Programa Escola de Conselhos firmou parceria com a Secretaria dos Direitos Humanos da Presidência da República, por meio da Secretaria Nacional de Promoção dos Direitos Humanos de Crianças e Adolescentes, com vista a proceder um amplo processo de Avalição das Escolas de Conselhos implantadas nas Unidades Federadas, alcançando a participação de onze Escolas no sentido restrito do projeto e mais de sete iniciativas no desenvolvimento de algumas atividades que previam a realização de dois encontros dos Núcleos de Formação Continuada/ Escola de Conselhos, onde vários estados estiveram representados.

Como produtos desse processo, os encontros produziram parâmetros para implantação e funcionamento dos Núcleos de Formação Continuada/ Escola de Conselhos, Matriz Nacional Curricular para formação de Conselheiros e ainda a indicação da criação da Escola Nacional de Conselhos, uma instância de apoio e consulta técnica. Essa cooperação possibilitou ainda a publicação pela Editora UFMS.

Em 2010, novos desafios foram postos à equipe do Programa Escola de Conselhos, a execução de um projeto denominado de Apoio Geral à Gestão Nacional do PAIR que compreendia dar assistência técnica a todos os estados que desenvolviam a metodologia do PAIR, representados em dezessete unidades da federação e ainda a execução do processo de implantação do programa em cinco capitais estaduais que não se apresentaram junto à Secretaria de Direitos Humanos, no Edital para financiamentos dessa ação. Assim, a Secretaria propôs que a equipe apresentasse uma proposta visando à implantação do Programa nas cidades de Curitiba (PR), Maceió (AL), Porto Alegre (RS), São Paulo (SP) e Vitória (ES). Para tanto, foram feitos contatos com as universidades locais visando à identificação de profissionais que pudessem assumir a coordenação local desse processo. Foram contatadas também autoridades estaduais e municipais visando ao engajamento no processo.

No processo de implantação do PAIR nas cinco capitais, no decorrer de 2010 a 2012, foram executadas as fases metodológicas do Programa, guardando 
algumas variações em respeito às proposições realizadas pelos parceiros técnicos locais. Destacam-se, nestas parcerias técnicas, a atuação de pesquisadores, docentes e orientandos de pós-graduação da USP, UFES, UFAL, UFRS e UFPR. A equipe do programa procedeu o repasse da metodologia e fez o acompanhamento e assessoramento técnico permanente às equipes locais.

Nessa ação, em cada uma das cidades, foram produzidos cadernos de texto, visando à capacitação dos agentes da rede de atendimento e proteção.

Ainda em 2010, teve início o Curso de Formação Continuada de Conselheiros de Direitos e Tutelares de Mato Grosso do Sul dentro dos parâmetros trazidos pela Escola Nacional de Conselhos, financiado pela Secretaria de Direitos Humanos, tendo sua finalização em 2012. Como nas demais atividades, essa ação teve como um de seus produtos publicação feita pela Editora UFMS, conforme QUADRO 1.

Quadro 1-Publicações da Escola de Conselhos

\begin{tabular}{|c|c|c|}
\hline Título do projeto & Título & ISBN \\
\hline $\begin{array}{c}1^{\circ} \text { Curso de Formação e } \\
\text { Informações em Políticas } \\
\text { Públicas para Infância e } \\
\text { Juventude }\end{array}$ & $\begin{array}{c}\text { Cadernos Caminhos para } \\
\text { a Cidadania-Infância e } \\
\text { Juventude, Desafios para o } \\
\text { Século XXI, }\end{array}$ & \\
\hline $\begin{array}{c}2^{\circ} \text { Curso de Formação e } \\
\text { Informações em Políticas } \\
\text { Públicas para Infância e } \\
\text { Juventude }\end{array}$ & $\begin{array}{l}10 \text { Anos de Estatuto - A } \\
\text { construção da cidadania da } \\
\text { criança e do adolescente }\end{array}$ & ISBN.85.85917-77-6 \\
\hline $\begin{array}{l}\text { Formação Nacional de } \\
\text { Conselheiros Tutelares }\end{array}$ & $\begin{array}{c}\text { Cadernos Caminhos para } \\
\text { Cidadania Estatuto da Criança } \\
\text { e o do Adolescente-Uma } \\
\text { Década de Direitos, Avaliando } \\
\text { Resultados e Projetando o } \\
\text { Futuro }\end{array}$ & ISBN. 85.85917-77-6 \\
\hline \multirow{2}{*}{$\begin{array}{c}\text { "Programa de Ações } \\
\text { Integradas e Referenciais } \\
\text { de Enfrentamento à } \\
\text { Violência Sexual contra } \\
\text { Crianças e Adolescentes no } \\
\text { Território Brasileiro - PAIR" }\end{array}$} & $\begin{array}{l}\text { Avaliação do Processo de } \\
\text { Implantação do Pair }\end{array}$ & ISBN 978-85-7613-143-4 \\
\hline & $\begin{array}{c}\text { Consolidando a Experiência do } \\
\text { Pair }\end{array}$ & ISBN 978-85-7613-142-7 \\
\hline \multirow[t]{3}{*}{ Escola que Protege } & $\begin{array}{c}\text { A menina e o menino que } \\
\text { brincavam de ser... }\end{array}$ & ISBN978-85-7613-241-7 \\
\hline & $\begin{array}{l}\text { Entre explosões e corte na } \\
\text { barriga: as curiosidades de } \\
\text { Rafael }\end{array}$ & ISBN978-85-7613-242-4 \\
\hline & $\begin{array}{l}\text { Entre sementes e cegonhas: as } \\
\text { curiosidades de Gabriela }\end{array}$ & ISBN978-85-7613-243-1 \\
\hline $\begin{array}{l}\text { Expansão do Pair em Mato } \\
\text { Crosso do Sul }\end{array}$ & $\begin{array}{l}\text { Expansão do Pair em Mato } \\
\text { Crosso do Sul }\end{array}$ & ISBN978-85-7613-415-2 \\
\hline
\end{tabular}




\begin{tabular}{|c|c|c|}
\hline \multirow{7}{*}{$\begin{array}{c}\text { Formação Continuada de } \\
\text { Socioeducadores de Mato } \\
\text { Grosso do Sul }\end{array}$} & $\begin{array}{l}\text { Caderno Formação Continuada } \\
\text { de Socioeducadores Cd } 1\end{array}$ & CDD(22)362.70981.37178981 \\
\hline & $\begin{array}{l}\text { Caderno Formação Continuada } \\
\text { de Socioeducadores Cd } 2\end{array}$ & ISBN978-85-7613-265-3 \\
\hline & $\begin{array}{l}\text { Caderno Formação Continuada } \\
\text { de Socioeducadores Cd } 3\end{array}$ & ISBN978-85-7613-427-7 \\
\hline & $\begin{array}{l}\text { Caderno Formação Continuada } \\
\text { de Socioeducadores Cd4 }\end{array}$ & ISBN978-85-7613-437-4 \\
\hline & $\begin{array}{c}\text { Caderno Formação Continuada } \\
\text { de Socioeducadores } \mathrm{Cd} 5\end{array}$ & ISBN978-85-7613-479-4 \\
\hline & $\begin{array}{l}\text { Caderno Formação Continuada } \\
\text { de Socioeducadores Cd6 }\end{array}$ & ISBN978-85-7613-519-7 \\
\hline & $\begin{array}{l}\text { Adolescentes em conflito com a } \\
\text { Lei-Fundamentos e Práticas da } \\
\text { Socioeducação }\end{array}$ & ISBN978-85-7613-376-6 \\
\hline $\begin{array}{l}\text { Estratégia Regional de } \\
\text { Enfrentamento ao Tráfico } \\
\text { de Crianças e Adolescentes } \\
\text { para fins de Exploração } \\
\text { Sexual }\end{array}$ & $\begin{array}{c}\text { Estratégia Regional de } \\
\text { Enfrentamento ao Tráfico de } \\
\text { Crianças e Adolescentes para } \\
\text { fins de Exploração Sexual }\end{array}$ & ISBN 978-85-7613-425-1. \\
\hline $\begin{array}{c}\text { Formação Continuada de } \\
\text { Conselheiros de Direitos e } \\
\text { Tutelares }\end{array}$ & $\begin{array}{c}\text { Formação Continuada de } \\
\text { Conselheiros de Direitos e } \\
\text { Tutelares }\end{array}$ & ISBN978-85-7613-397-2 \\
\hline $\begin{array}{l}\text { Avaliação das Escolas de } \\
\text { Conselhos do Brasil }\end{array}$ & $\begin{array}{l}\text { Avaliação das Escolas de } \\
\text { Conselhos do Brasil }\end{array}$ & ISBN 978-85-7613-502-9 \\
\hline $\begin{array}{l}\text { Apoio Ceral à Cestão } \\
\text { Nacional do Pair }\end{array}$ & $\begin{array}{l}\text { Violência Sexual contra } \\
\text { Crianças e Adolescentes na } \\
\text { Cidade de São Paulo }\end{array}$ & ISBn978-85-7613-355-1 \\
\hline $\begin{array}{c}\text { Conselheiros de Direitos e } \\
\text { Tutelares de Mato Grosso } \\
\text { do Sul 2010/2012. }\end{array}$ & $\begin{array}{l}\text { Formação Continuada de } \\
\text { Conselheiros de Direitos e } \\
\text { Tutelares de Mato Grosso do Sul } \\
\text { 2010/2012"-1. }\end{array}$ & ISBN 978-85-7613-524 \\
\hline
\end{tabular}

Fonte: CATÁlogo Escola de ConselHos - 2019.P.

No tocante à dimensão nacional das ações do Programa Escola de Conselhos é bem evidenciado o período que vai de 2003 a 2013, quando esteve na retaguarda da Secretaria Nacional de Promoção dos Direitos Humanos de Crianças e Adolescentes, oferecendo suporte técnico e apoio no desenvolvimento de políticas públicas em três grandes áreas de atuação daquela Secretaria: Fortalecimento dos Conselhos de Direitos e Tutelares - com a disseminação da metodologia de formação e a criação da Escola de Conselhos e da Escola Nacional de Conselhos; Formação de Socioeducadores com a construção de uma plataforma nacional de formação executada pela Universidade Nacional de Brasília (UnB) e da Escola Nacional de Socioeducação; e Ações de Proteção aos Direitos Sexuais de Crianças e Adolescentes, com o 
desenvolvimento, disseminação e execução do Pair no território nacional e nas regiões de fronteira.

Embora incorporada ao PPA, a partir de 2012, ocorreu um gradativo e constante recrudescimento dos recursos destinados às ações de formação de conselheiros municipais e tutelares e, por consequência comprometeu a execução do Objetivo Estratégico da Secretaria Nacional de Promoção dos Direitos da Criança e do Adolescente, que estabelecia: "Implantar Escolas de Conselhos nos estados e no Distrito Federal, com vistas a apoiar a estruturação e qualificação da ação dos Conselhos dos Direitos e Conselhos Tutelares".

Coincidentemente, assim como no âmbito dos Direitos Humanos, nos anos que se seguiram, ocorreu uma gradativa e constante diminuição dos recursos destinados ao financiamento da extensão universitária por parte do MEC, chegando a zerar os repasses a partir de 2017, o que deixou a área à mercê do orçamento de cada universidade.

A partir de 2014, o Programa Escola de Conselhos passou a atuar estritamente ligado aos recursos próprios da UFMS, valendo-se de projetos aprovados nos editais internos, com pouca capacidade de financiamento de despesas, limitando-se, na maioria das vezes, ao pagamento de bolsas para os alunos extensionistas vinculados aos projetos.

Como sua demanda já está consolidada, a procura dos conselhos pela participação nas atividades de formação continuada se apresentava nos mesmos níveis daquelas vivenciadas em períodos em que havia mais recursos oriundos das parcerias com a SDH ou dos editais do MEC.

Esse processo possibilita algumas reflexões sobre aspectos não comumente observados, posto que são invisíveis diante do modus operandi das instituições públicas do país que, por reproduzir as relações do modo de produção capitalista com a apropriação do conhecimento e da capacidade de criação humana para o fortalecimento dos processos de acumulação, normalmente produzem as soluções sem o necessário respaldo e efetiva participação das partes interessadas. Nesse sentido, é comum a adoção de matrizes públicas de intervenção a partir dos interesses dos agentes públicos, sem prévia manifestação dos destinatários ou dos segmentos interessados.

Faz-se necessário ainda recuperar a proposta estabelecida pelo Sindicato Nacional dos Docentes das Instituições de Ensino Supeior (ANDES), no período pré-constitucional, quando se entendia que a indissociabilidade "reflete um conceito de qualidade do trabalho acadêmico que favorece a aproximação 
entre universidade e sociedade, a auto-reflexão crítica, a emancipação teórica e prática dos estudantes e o significado social do trabalho acadêmico" (ANDES, 2003, p.30).

Segundo a Associação, a concretização da dissociabilidade deve desencadear a formulação de "projetos coletivos de trabalho que se referenciem na avaliação institucional, no planejamento das ações institucionais e na avaliação que leve em conta o interesse da maioria da sociedade" (ANDES, 2003, p.30).

Ao pesquisar sobre os cenários da extensão universitária, tendo como pano de fundo o binômio universidade sociedade, Silva (2006) verifica que há uma clara tendência a associar a responsabilidade social da universidade às funções da extensão:

[...] Ilustrativamente, a pesquisa bibliográfica e de campo que realizei apontou que, ao se pôr em evidência a temática função social da universidade, há um entendimento que a limita na esfera da extensão universitária. Ou seja: a análise a respeito da responsabilidade social da universidade em geral apresenta a extensão como a "porta de entrada" da instituição em relação às temáticas sociais. Esse ponto de vista têm sido, ainda que não generalizadamente, suscetível às críticas. Por isso, explicitar o conceito de extensão, superar a imprecisão existente assume importância, sobretudo pelo que pode contribuir no sentido de construir a identidade da universidade, questão considerada crucial, hoje mais do que nunca (SILVA, 2006, p.52).

A extensão consiste em um dos pilares da universidade: a indissociabilidade entre ensino, pesquisa e extensão; é essa relação que fortalece essa instituição, inclusive destinando elementos sociais nessas três esferas e não somente para a extensão. A Escola de Conselhos enquanto iniciativa da universidade visou dar praticidade aos princípios e conhecimentos produzidos no campo dos direitos humanos, ancorada na compreensão do alcance dos direitos sociais básicos do cidadão.

Quando a equipe do Programa Escola de Conselhos organiza um projeto de extensão, em grande parte, o faz para atender demandas surgidas no decurso das suas atividades anteriores, normalmente diante de situações percebidas como não alcançadas pelas ações executadas ou que estão em curso, quer seja decorrente da ação extensionista, quer seja pelas políticas públicas vigentes.

Em 2006, o Programa Escola de Conselhos exercia um papel preponderante na inserção da Instituições de Ensino Superior no aprimoramento das 
Políticas Sociais, nesse momento, crescia no âmbito da Secretaria Nacional de Promoção dos Direitos da Criança (sucessora do DCA) a ideia de se fomentar a implantação de Escolas de Conselhos em outras Unidades da Federação.

A Resolução do CONANDA n 112, de 27 de março de 2006, tratou de regulamentar e estabelecer parâmetros de formação continuada dos operadores do sistema de garantia dos direitos da criança e do adolescente.

No processo de construção do Programa Nacional de Direitos Humanos III, consta por meio da Diretriz 8, o compromisso com a promoção dos direitos de crianças e adolescentes para o seu desenvolvimento integral, de forma não discriminatória, assegurando seu direito de opinião e participação, estabelecendo por meio do Objetivo estratégico II, a tarefa de consolidar o Sistema de Garantia de Direitos de Crianças e Adolescentes, com o fortalecimento do papel dos Conselhos Tutelares e de Direitos, onde consta especificamente no item b (BRASIL, 2010, p. 76):

a) $[\ldots]$.

b) Implantar Escolas de Conselhos nos estados e no Distrito Federal, com vistas a apoiar a estruturação e qualificação da ação dos Conselhos dos Direitos e Conselhos Tutela

c) $[\ldots . .$.$] .$

Segundo os registros oficiais da época, trazidos no âmbito do Portal dos Direitos da Criança e do Adolescente do Governo Federal:

As Escolas de Conselhos apresentam-se como relevantes estratégias para consolidação de núcleos de referência para formação continuada de conselheiros dos direitos e conselheiros tutelares e proporcionam a tais atores as condições necessárias para superarem, progressivamente a carência de preparo para o exercício de suas funções de forma a assegurar uma atuação qualificada dos atores na promoção e defesa dos direitos de crianças e adolescentes.

VO Programa Escola de Conselho nasce em uma pequena e despretensiosa iniciativa (resposta institucional) de extensão universitária, dirigida ao aprimoramento da participação democrática e dos processos de representação e controle social em um estado que tem apenas setenta e nove municípios. Ganha corpo e notoriedade nacional, ultrapassa as barreiras desse território ao se constituir referência técnica para países vizinhos. Seu êxito, por certo, precisa ser melhor analisado, mas há que pontuar que, seu modo operacional foi estabelecido na contramão dos modos vigentes, rompendo com a cultura 
dos monopólios do conhecimento - monopólio acadêmico/monopólio classe dominante.

A densidade e intensidade dessas demandas absorvidas pela extensão e promovidas no âmbito do Programa Escola de Conselhos guardava, e por hora ainda guarda, cumprimento de exigência constitucional e das legislações decorrentes, em muitos casos eram condicionantes para a transferência dos recursos da União para estados e municípios ou mesmo para as subvenções sociais. Por certo, uma receita que tinha tudo para dar certo, pois os ingredientes de alta qualidades estavam todos dispostos - princípios normativos, inciativas sociais, iniciativas institucionais, etc. Além dos ingredientes, restou definir pessoas e métodos para processar isso tudo e produzir respostas à altura das exigências. Saber ler a demanda e, junto com os seus demandatários, constituir um plano de trabalho, talvez explique parte do êxito obtido.

A precariedade das estruturas públicas para dar operacionalidade aos princípios legais e normativos vigentes, o sucesso das primeiras experiências vivenciadas da extensão praticada pelo Programa Escola de Conselhos foi determinante para o surgimento das mais variadas demandas nos níveis nacional, estadual e municipal. Até 1997, não havia registro de institucionalização da função de formação de agentes públicos que ocupavam lugar nos órgãos colegiados de controle e consulta em políticas públicas. A simples execução de uma ação dessa natureza no âmbito de uma universidade pública deu luz à possibilidade de se replicar a iniciativa, pelo grau de confiabilidade e confiança que parecia inspirar - isso fruto do subjetivismo cultural.

\section{CONSIDERAÇÕES FINAIS}

Não se pode estabelecer que o Programa Escola de Conselhos foi ou seja uma solução para as dificuldades pelas quais passam as áreas em que atua, porém se constitui numa ação institucional que oportuniza estratégias para que agentes públicos e sociais que operam políticas públicas acessem conhecimentos, métodos e ferramentas que facilitam o processo de organização de suas ações e possam alterar suas rotinas de forma a alterar os resultados de suas ações. Nesse sentido, o Programa se aproxima do que Santos estabeleceu como objetivo prioritário, sufragado democraticamente no interior da universidade: "o apoio solidário na resolução dos problemas da exclusão e da 
discriminação sociais e de tal modo que nele se dê voz aos grupos excluídos e discriminados" SANTOS (2008, p.54).

As ações do Programa Escola de Conselhos ganham força no momento em que expandem as parcerias com instâncias do poder público federal, em especial com as áreas de direitos humanos, educação e assistência social. Essas ações refletiram em parcerias com entes das esferas estaduais e municipais, visando à implementação de políticas públicas, integrando a UFMS e um grande número de universidades públicas. O pano de fundo desses processos esteve voltado à superação da violência contra segmentos da população, notadamente de crianças e adolescentes, por meio de propostas voltadas ao comprometimento das instituições públicas de ensino superior, promovendo, de certo modo, alteração nos padrões vigentes e a valorização da extensão. Esse processo por certo contribui com a possibilidade do secular desejo latino-americano em realizar projetos e programas voltados para o diálogo com os conhecimentos extramuros e com o mesmo valor que cercam o ensino e a pesquisa.

Por certo que a experiência desenvolvida no âmbito dos projetos de extensão que compreendem o Programa Escola de Conselhos não se constitui em uma matriz de resistência ao modo societário capitalista no âmbito da educação superior, tampouco surgiu nessa perspectiva ou com essa finalidade. No entanto, a maneira como visualiza, reflete e executa ações extensionistas, aproxima-se de forma singular das demandas da sociedade no que diz respeito à sua constitucional prerrogativa e natural necessidade de participação no processo de organização e controle das políticas públicas.

É importante não perder de vista que ao se pesquisar sobre a extensão universitária, está se pesquisando sobre a educação superior, sendo impossível deixar de considerar que os processos e conteúdos desenvolvidos na extensão estão diretamente vinculados à produção e organização do conhecimento, bem como contribui para esse processo. O modo de organização de uma sociedade influencia na organização de uma universidade e reflete diretamente na forma e no conteúdo que cercam a extensão.

Por fim, compreendemos a extensão como expressão social, política e econômica de um tempo histórico em que a educação superior é idealizada para desenvolver ações de cunho social, mas relacionadas ao ensino e à pesquisa. Os embates materializados nos documentos e políticas que normatizam a extensão, também evidenciam aspectos sociais como destaque para a extensão 
nas universidades brasileiras. Entretanto, ainda há um caminho importante a se percorrer na luta pela educação pública, gratuita e de qualidade, e nele a extensão representa um espaço importante a ser conquistado.

\section{REFERÊNCIAS}

ANDES-SN. Proposta do ANDES-SN para a universidade Brasileira. Cadernos ANDES no 2. 3. ed. atualizada e revisada. Brasília: ANDES-SN, 2003.

BRASIL. Constituição da República Federativa do Brasil de 1988. Disponível em: http://www.planalto.gov.br/ccivil_03/Constituicao/Constituicao.htm. Acesso em 01.07.2017. Acesso em: 12 nov. 2018.

BRASIL. Resolução do CONANDA n ${ }^{\circ}$ 112, de 27 de março de 2006. Disponível em: https://www.direitosdacrianca.gov.br/novodireito/conanda/resolucoes/112-resolucao-112-de-27-de-marco-de-2006/view. Acesso em: 12 nov. 2018.

BRASIL. Programa Nacional de Direitos Humanos (PNDH-3). Secretaria de Direitos Humanos da Presidência da República. Brasília: SDH/PR, 2010.

FORPROEX. Política Nacional de Extensão Universitária. Manaus/AM. 2012. Disponível em: https://www.ufmg.br/proex/renex/images/documentos/2012-07-13-Politica-Nacional-de-Extensao.pdf. Acesso em: $10 \mathrm{dez} .2018$.

BRASIL. MEC. Resolução CNE/CES 7/2018. Diário Oficial da União, Brasília, 19 de dezembro de 2018, Seção 1.

MÉZARÓS, Instívan. A Educação para Além do Capital. São Paulo: Boitempo Editorial, 2012.

MOTTI, A. J. A.; MACIEL, C. E. ; PEDROZO, J. C. . Estudos sobre a contribuição de ações de extensão universitária na democratização do acesso ao conhecimento produzido no âmbito da ufms. In: XIV CONGRESSO INTERNACIONAL DE DIREITOS HUMANOS, 2017, campo grande. Anais do XIV Congresso Internacional de Direitos Humanos, 2017. V. 1. P. 1-21.

SANTOS, Boaventura de Souza, FILHO, Naomar de Almeida Filho, A universidade no Século XXI: Para uma universidade Nova. MIMEO, Coimbra, outubro 2008.

SILVA, Maria das Graças M. Extensão: a face social da universidade? Campo Grande: Editora da UFMS, 2000. 